\title{
Drug-drug interactions with direct-acting antivirals - less is more
}

\author{
Grace Lai-Hung Wong ${ }^{1,2,3}$ \\ 'Department of Medicine and Therapeutics, ${ }^{2}$ Medical Data Analytic Centre (MDAC), ${ }^{3}$ Institute of Digestive Disease, The Chinese Univer- \\ sity of Hong Kong, Hong Kong, China
}

Keywords: Hepatitis C; Antiviral agents; Drug-related side effects and adverse reactions

\section{See Article on Page 186}

World Health Organization published the first global health sector strategy on viral hepatitis in June 2016, a strategy that contributes to the proposed targets for the reduction of chronic viral hepatitis incidence and mortality of $90 \%$ and $65 \%$ respectively by 2030.' Now, we are lucky enough to have highly effective directacting antivirals (DAAs) for patients infected with hepatitis C virus $(\mathrm{HCV})$, which achieve sustained virologic response in more than $95 \%$ of HCV patients. ${ }^{2}$ Yet, it remains challenging to achieve micro-elimination in some special populations, namely patients with chronic kidney disease (CKD), and especially those on hemodialysis. ${ }^{3}$ On major issue is the potential drug-drug interaction (DDI) between DAAs and the comedications of these patients, which are often a handful in terms of numbers and classes in view of their multiple comorbidities. ${ }^{4,5}$

In the current issue of the Clinical and Molecular Hepatology, Hsu and colleagues ${ }^{6}$ reported the Taiwanese nationwide cohort of 2,015 hemodialysis patients, among whom 169 patients were screened positive for HCV RNA. The authors described in much details the comedications and their potential DDIs with DAAs. Interestingly, lipid-lowering agents, which were used in more than one-third of patients, accounted for the majority of red-category DDIs. Elbasvir/grazoprevir was found to be the DAA regimen with fewest potential DDIs $(0.3 \%$ only), whereas the triple therapy sofosbuvir/velpatasvir/voxilaprevir had the most $(5.6 \%){ }^{6}$ The latter was not surprising as there are three DAA agents, instead of two in most other cases, in this regimen.

The findings of this study are of clinical importance as it may guide us to select the most suitable DAA regimens for our hemodialysis patients. This is a crucial part of HCV elimination as it would minimize the risk of nosocomial transmission of HCV in dialysis centres. This is particularly true for the treatment of hemodialysis patients who get acute hepatitis $C$ as the treatment window is limited. ${ }^{8}$ While elbasvir/grazoprevir is suitable for patients CKD infected with genotype $1 \mathrm{HCV}$, glecaprevir/pibrentasvir is another option for CKD patients with the advantage of its pangenotypic efficacy. ${ }^{9}$ An detailed implantation guideline for managing HCV infection in CKD patients was published earlier this year to provide more specific guidance. ${ }^{10}$

Another difficult-to-treat special population would be people

\section{Abbreviations:}

CKD, chronic kidney disease; DAAs, direct-acting antivirals; DDI, drug-drug interaction; $\mathrm{HCV}$, hepatitis $\mathrm{C}$ virus

\section{Corresponding author: Grace Lai-Hung Wong}

Department of Medicine and Therapeutics, 9/F Prince of Wales Hospital, Shatin, Hong Kong

Tel: +852-2632-3538, Fax: +852-2637-3852

E-mail:wonglaihung@cuhk.edu.hk

https://orcid.org/0000-0002-2863-9389 


\section{CLINCAL and MOLECULAR
HEPATOLOGY}

who inject drugs, as they often receive opioid substitute therapy and also many other comedications. ${ }^{11}$ The current study by Hsu et al. ${ }^{6}$ has also provided important data to support the preferred DAA regimens which may minimise the DDIs. To achieve HCV elimination, a simplified DAA regimen with minimal DDIs would be an important tool.

\section{Conflicts of Interest}

The author has no conflicts to disclose.

\section{REFERENCES}

1. World Health Organization (WHO). Combating hepatitis B and C to reach elimination by 2030. WHO web site, <www.who.int/hepatitis/ publications/hep-elimination-by-2030-brief/en/>. Accessed on 9 Oct 2020.

2. Parigi TL, Torres MCP, Aghemo A. Upcoming direct acting antivirals for hepatitis $C$ patients with a prior treatment failure. Clin Mol Hepatol 2019;25:360-365.

3. Ko SY, Choe WH. Management of hepatitis C viral infection in chronic kidney disease patients on hemodialysis in the era of directacting antivirals. Clin Mol Hepatol 2018;24:351-357.

4. Huang CF, Yu ML. Unmet needs of chronic hepatitis $C$ in the era of direct-acting antiviral therapy. Clin Mol Hepatol 2020;26:251-260.

5. Subramaniam S, Wong VW, Tse YK, Yip TC, Chan HL, Wong GL.
Impact of diabetes mellitus and hepatitis B virus coinfection on patients with chronic hepatitis C: a territory-wide cohort study. J Gastroenterol Hepatol 2018;33:934-941.

6. Hsu PY, Wei YJ, Lee JJ, Niu SW, Huang JC, Hsu CT, et al. Comedications and potential drug-drug interactions with direct-acting antivirals in hepatitis C patients on hemodialysis. Clin Mol Hepatol 2021; 27:186-196.

7. Fabrizi F, Messa P. Transmission of hepatitis C virus in dialysis units: a systematic review of reports on outbreaks. Int J Artif Organs 2015;38:471-480.

8. He YL, Yang SJ, Hu CH, Dong J, Gao H, Yan TT, et al. Safety and efficacy of sofosbuvir-based treatment of acute hepatitis $C$ in endstage renal disease patients undergoing haemodialysis. Aliment Pharmacol Ther 2018;47:526-532.

9. Yap DYH, Liu KSH, Hsu YC, Wong GLH, Tsai MC, Chen CH, et al. Use of glecaprevir/pibrentasvir in patients with chronic hepatitis $\mathrm{C}$ virus infection and severe renal impairment. Clin Mol Hepatol 2020;26:554-561.

10. Li PK, Bavanandan S, Mohamed R, Szeto CC, Wong VW, Chow KM, et al. 2018 Kidney disease: improving global outcomes (KDIGO) hepatitis $C$ in chronic kidney disease guideline implementation: Asia summit conference report. Kidney Int Rep 2020;5:1129-1138.

11. Wong GL, Chan HL, Loo CK, Hui YT, Fung JY, Cheung D, et al. Change in treatment paradigm in people who previously injected drugs with chronic hepatitis $C$ in the era of direct-acting antiviral therapy. J Gastroenterol Hepatol 2019;34:1641-1647. 